\title{
Corruption and positive selection in privatization
}

\author{
Raluca E. Buia, M. Cristina Molinari* \\ Department of Economics, Ca' Foscari University of Venice, San Giobbe 873, 30121 Venice, Italy
}

\section{A R T I C L E I N F O}

\section{Article history:}

Received 22 November 2011

Accepted 14 May 2012

Available online 19 June 2012

\section{Keywords:}

Corruption

Privatization

Private versus public provision

\begin{abstract}
A B S T R A C T
We consider the supply of a public good based on a publicly owned facility. The Government has a choice between provision in-house and privatizing the facility and then outsourcing the production. In particular, we focus on corruption in the decision to privatize and on its effect on social welfare when there is asymmetric information on the public and private manager's efficiency. Our analysis shows that a corrupt Government, that chooses to privatize only in exchange for a bribe, makes a positive selection on the private firm's efficiency and, thus, may have a positive effect on social welfare.
\end{abstract}

(c) 2012 University of Venice. Published by Elsevier Ltd. All rights reserved.

\section{Introduction}

Corruption is usually defined as the use of public office for private gains by bureaucrats or politicians. Economists have always been interested in the effects of corruption on welfare and the literature on this subject is by now a large chapter of public economics, as reviewed in Bardhan (1997), Jain (2001) and Aidt (2003). A strand of this literature maintains that some corruption might be desirable, by helping individuals and firms to reduce delay in administrative procedures and efficiently solving queuing problems (see, for example, Lui, 1985). This is known as the "grease the wheel" hypothesis. The opposite "sand in the wheel" hypothesis views corruption less positively (Murphy et al., 1993).

Empirically, the question whether corruption greases or sands the wheels of the economy is not settled: despite many found a negative effect of corruption on important macroeconomic variables such as growth, GDP per capita, FDI and others (as surveyed in Bardhan, 1997), recent results show that the economic effects are ambiguous (de Vaal and Ebben, 2011; Dreher and Herzfeld, 2005; Dong and Torgler, 2010; Everhart et al., 2009; Halkos and Tzeremes, 2010).

A special case for the study of corruption is the process of privatization. Privatization is often seen as a way to reduce the opportunities for corruption and to enhance efficiency. The process of privatization itself, however, is an occasion for public bureaucrats to collect bribes: firms may pay off officials in order to influence the decision whether to sell stateowned enterprises, at what price and to whom. Looking at the experiences of privatization in the East European countries, Latin America and Asia in the last 25 years, one comes to the conclusion that bribery seems to be a common occurrence (Kaufmann and Siegelbaum, 1997; Chong and Lopez de Silanes, 2004; Lu et al., 2008). But should we be concerned? Does corruption forfeit most of the advantages that privatization was intended for, as most think, or is it possible that corruption plays the role of an efficient allocation mechanism? This is the question that we address in this paper.

The issue has been raised before in the literature, although not in a formal model, and the conclusions are not univocal. On the one hand, along with the tradition that corruption might be desirable, some think that bribery can reproduce the efficiency consequences of a competitive bidding procedure: the most efficient producer has the largest surplus, therefore he can afford the largest bribe. However, even the proponents of such view recognize that the Coasian bargaining between

\footnotetext{
* Corresponding author. Tel.: +39041234 9139; fax: +390412349176

E-mail address: cmolinar@unive.it (M.C. Molinari).
} 
the bureaucrat and the private firms might fall short of achieving efficiency when we bring in issues of asymmetric information, uncertainty (given the risk of being caught) and contract enforceability (Bardhan, 1997). On the other hand, and this seems to be the prevailing view, most authors think that corruption is the source of large inefficiencies in the process of privatization and that the necessity to pay a bribe plays the role of a barrier to entry (for example, RoseAckerman, 1997, 1999).

The goal of this paper is to disclose one of the mechanisms through which corruption could play a positive role. We provide a formal model of the effects of corruption in the decision to privatize and we use it to investigate the selection properties of bribing in the presence of asymmetric information on the firms' efficiency. Our analysis shows that a corrupt Government, that chooses to privatize only in exchange for a bribe, has a positive effect on expected social welfare. This result is achieved because the bribe asked by the public official plays the role of a positive selection device. Therefore, the result holds despite the asymmetry of information; in fact, it holds because of it.

We consider a Government that wants to supply a public good and has a choice between provision in-house and outsourcing. The latter is conditional on privatizing a facility necessary for the production of the good; think, for example, to school education where the facility is the school building. Our starting point is a model, along the lines of Hart et al. (1997), analyzing the trade-off between public and private provision (in terms of cost and quality of the good) in which we introduce corruption in the privatization process: a corrupt politician chooses to privatize only when the private firm agrees to pay a bribe asked on the basis of a take it or leave it offer. The public official, not knowing the efficiency of the private firm, asks for an "average" bribe which turns out to be too high for low efficiency firms. Consequently, he privatizes only when the efficiency of the firm is above average and in this way he raises the ex post average efficiency of the privatized firm above the ex ante average.

There are few other contributions that analyze the consequences of corruption in the privatization process. In Bjorvatn and Soreide (2005), differently from our model, the decision to privatize is given but the privatization price and the market concentration after privatization are endogenous. The main result of the paper is that social welfare is lower the higher the level of corruption, due to higher concentration. In their model the efficiency of the firm is not an issue. In Laffont and Meleu (1999), instead, the choice to privatize is endogenous and it occurs when politicians can recoup the lost gains they derived from the public firm with shares of the private one; this leads to a u-shaped relationship between the level of corruption and privatization. In this paper the driving force is not corruption in the decision to privatize but corruption, and the associated gains, before it.

Perhaps more similar in spirit to our paper are Beck and Maher (1986) and Lien $(1986,1990)$. These papers look at the relationship between corruption and procurement; in particular, they study a bribery game where firms compete to win a Government contract and there is asymmetric information on the private firms' cost of providing the good. Instead of assuming that the public official makes a take-it-or-leave-it request for a bribe, as we do, they consider the case of multiple firms bidding competitively their bribes. They show that there is an isomorphism between bribery and a competitive bidding procedure such that both mechanisms lead to the ex post efficient allocation. Of course, this is true as long as the public official is only influenced by the size of the bribe. And problems may arise if bribes are forfeited so that even the losers of the bribing game pay the cost of their bribe, as pointed out by Clark and Riis (2000).

The remainder of this paper is structured as follows. Section 2 presents a model of the trade-off between public and private provision without corruption and compares these two alternative regimes in terms of social welfare. Section 3 introduces corruption and studies its effects. Section 4 discusses the generality of the result. Finally, Section 5 concludes.

\section{Provision without corruption}

We consider the choice by the Government to supply goods such as hospitals, school or prison services either in-house, i.e. through public employees, or to contract them out to a private supplier. In this section we shall present a simple benchmark model of the trade-offs between public and private provision without corruption, that is with a benevolent politician whose payoff is equal to social welfare. Our model is a special case of Hart et al. (1997) ${ }^{1}$ to which we refer for detailed proofs and motivation.

The Government owns a facility (for example a school) that is necessary to provide a good. The difference between public and private provision hinges on the residual control rights of this facility under the hypothesis that contracts are incomplete. As argued in Shleifer (1998), this difference would disappear if complete contracts could be written.

\subsection{Private provision without corruption}

If private provision is chosen, the facility needs to be privatized. The Government and a risk neutral private manager can write a long-term contract specifying the prices $P_{F}$ of the facility and $P_{0}$ of the public good. This basic version of the good brings social benefit $B_{0}$ at cost $C_{0}$, the latter to be borne by the private manager. For convenience let $P_{0}-C_{0}=0$. We also assume that $P_{F}$ is small enough for privatization to occur.

\footnotetext{
${ }^{1}$ In particular, we consider the case $b(e)=\delta e, c(e)=\sigma \sqrt{e}, \beta=0, \lambda=1$.
} 
After the contract is signed, the manager chooses effort $e$; this effort not only lowers production costs by $\sigma \sqrt{e}$, where $\sigma \in[0,1]$ is a measure of the manager's cost reduction ability, but also decreases welfare by $\delta e, \delta \in[0,1]$, due to lower quality. Therefore, $e$ modifies the basic version of the good in the direction of not only lower cost but also lower quality.

We assume that exerting effort costs the manager $e$. Social welfare as a function of the manager's ability $\sigma$ and his effort $e$ is

$$
W=B_{0}-C_{0}+\sigma \sqrt{e}-\delta e-e .
$$

Effort, costs and benefits are not verifiable so they cannot be specified ex ante in the long-term contract. Since privatization gives the manager residual controls, the manager can implement any cost reduction he wishes, without Government's approval. It follows that equilibrium effort under private provision, denoted by $e_{P}$, is the solution to the following maximization problem:

$$
\max _{e} \sigma \sqrt{e}-e \text {. }
$$

By straightforward calculations we get that equilibrium effort is

$$
e_{P}=\frac{\sigma^{2}}{4}
$$

and equilibrium welfare under private provision as a function of $\sigma^{2}$ is

$$
W_{P}\left(\sigma^{2}\right)=B_{0}-C_{0}+\frac{\sigma^{2}}{4}(1-\delta) \text {. }
$$

\subsection{Public provision without corruption}

Consider now public provision. We assume that the description of the good is part of a contract between the Government and a risk neutral public employee and we now interpret $P_{0}$ as the wage the latter receives for providing (the basic version of) the good. Due to non-verifiability, $e$ cannot be specified by this contract.

When provision is done in-house, the public employee cannot implement cost reductions without Government approval because he does not have residual control rights on the facility; also, the cost reducing effort is embodied in the public employee's human capital, i.e. the Government cannot achieve cost reductions without the employee's participation. Therefore the Government and the employee get engaged in a renegotiation of their initial contract.

We assume that the gains achievable through renegotiation are split according to the Nash bargaining solution. Since in the absence of an agreement the basic good is produced, the employee's payoff after renegotiation is given by

$$
P_{0}-C_{0}+\frac{1}{2}(\sigma \sqrt{e}-\delta e)-e
$$

this is the payoff the employee maximizes when choosing the level of effort. Therefore, equilibrium effort under public provision, denoted by $e_{G}$, is

$$
e_{G}=\frac{\sigma^{2}}{4(2+\delta)^{2}}
$$

and equilibrium social welfare when the good is provided in-house is

$$
W_{G}\left(\sigma^{2}\right)=B_{0}-C_{0}+\sigma^{2} \frac{\delta+3}{4(2+\delta)^{2}} .
$$

\subsection{Evaluation of ownership structures without corruption}

In order to evaluate the efficiency of the two forms of provision we find the efficient cost reducing effort, denoted by $e^{*}$, as the solution to the following problem:

$$
\max _{e} B_{0}-C_{0}+\sigma \sqrt{e}-\delta e-e .
$$

The unique solution is

$$
e^{*}=\frac{\sigma^{2}}{4(\delta+1)^{2}} .
$$

Comparing the first best effort $e^{*}$ with the two equilibrium efforts $e_{P}$ of Eq. (1) and $e_{G}$ of Eq. (2), we see that $e_{G}<e^{*}<e_{P}$; thus, neither form of provision is first-best efficient. More precisely, on one hand $e^{*}<e_{P}$ because private provision gives too strong incentives to introduce cost reducing innovations. A private manager does not care about the negative externality that his effort has on social welfare; thus, his cost reducing effort is greater than the socially optimal one. On the other hand, $e_{G}<e^{*}$, i.e. the cost reducing effort under public provision is smaller than the first best effort, because a 
public manager gains only half of the benefits associated to his effort but he bears the whole cost; therefore, he has too little incentives to introduce cost reducing innovations.

Which form of provision is second-best efficient depends on the value of the parameters $\sigma$ and $\delta$, i.e. on the relative efficiency in cost reduction of the private manager with respect to the public employee and on the social costs of the cost reducing effort.

In particular, when the two managers have the same $\sigma$, the equation $W_{P}(\sigma)=W_{G}(\sigma)$ determines a threshold value $\bar{\delta}=\sqrt{2}-1 \simeq 0.4142$ such that private provision is better than public for $\delta<\bar{\delta}$ and, conversely, public provision is preferable otherwise. In other words, when the two managers have the same cost reducing efficiency, private provision is preferable if the social cost of effort, which is disregarded by a private manager, is not too large.

When, instead, the private and the public manager have different efficiencies in cost reductions, denoted respectively by $\sigma_{P}$ and $\sigma_{G}$, private provision is better than public if

$$
\frac{\sigma_{G}^{2}}{\sigma_{P}^{2}}<\frac{(1-\delta)(2+\delta)^{2}}{(\delta+3)}
$$

Since the expression on the right is decreasing in $\delta$, as $\delta$ increases the private manager needs higher and higher efficiency, compared to the public employee, in order to compensate the negative externality of the cost reduction.

\section{Provision with corruption}

We now introduce corruption. We assume that the choice whether to privatize the asset is taken by a corrupt politician who asks the private manager a bribe on the basis of a take-it-or-leave-it offer. If the manager refuses the offer, the good is provided by a public manager; if, instead, the bribe is paid, the facility is sold for a price $P_{F}$ and provision is contracted out.

The politician has incomplete information on both the private manager's and the public bureaucrat's cost reducing efficiency, that is on the pair $\left(\sigma_{P}, \sigma_{G}\right)$, where $\sigma_{P}$ and $\sigma_{G}$ are two independent random variables whose squared value $\sigma_{P}^{2}$ and $\sigma_{G}^{2}$ are both uniformly distributed in $[0,1]$.

Let $B$ be the bribe asked by the politician. An optimal choice of the private manager is to pay the bribe whenever the latter is smaller than his profit net of the price of the facility, i.e. when

$$
\sigma \sqrt{e}-e-P_{F} \geq B
$$

and refuse to pay otherwise. In what follows we set $P_{F}=0 .^{2}$

By substituting the equilibrium level of effort $e_{P}$ of Eq. (1) in the profit expression above, we get that only a private manager whose $\sigma_{P}^{2}$ is greater than $4 B$ pays the bribe.

By subgame perfection, the politician asks for a bribe $B^{*}=\frac{1}{8}$, where $B^{*}$ maximizes his expected revenue given the manager's decision to pay the bribe

$$
\max _{B} \int_{4 B}^{1} B d \sigma^{2} .
$$

We conclude that when the choice to privatize is made by a corrupt self-interested politician, in equilibrium provision is private for $\sigma_{P}^{2} \geq \frac{1}{2}$ and public otherwise.

In order to evaluate the consequences of corruption on social welfare we compute the ex ante expected social welfare with corruption, that we denote by $\bar{W}_{C}$. When $\sigma_{P}^{2}<\frac{1}{2}$ the private manager refuses to pay the bribe and provision is public; therefore, with probability one-half social welfare is the expected value with respect to $\sigma_{G}$ of $W_{G}\left(\sigma_{G}\right)$. When, instead, $\sigma_{P}^{2} \geq \frac{1}{2}$, the bribe is paid and the facility is privatized so that social welfare is equal to the expected value of $W_{P}\left(\sigma_{P}\right)$ conditional on $\sigma_{P}^{2} \geq \frac{1}{2}$. It follows that

$$
\bar{W}_{C}=\int_{0}^{1 / 2} \int_{0}^{1} W_{G}\left(\sigma_{G}^{2}\right) d \sigma_{G}^{2} d \sigma_{P}^{2}+\int_{1 / 2}^{1} W_{P}\left(\sigma_{P}^{2}\right) d \sigma_{P}^{2} .
$$

Define the ex ante expected social welfare under public provision $\bar{W}_{G}$ as

$$
\bar{W}_{G}=\int_{0}^{1} W_{G}\left(\sigma^{2}\right) d \sigma^{2}
$$

Then, we can write $\bar{W}_{C}$ as

$$
\bar{W}_{C}=\int_{0}^{1 / 2} \bar{W}_{G} d \sigma_{P}^{2}+\int_{1 / 2}^{1} W_{P}\left(\sigma_{P}^{2}\right) d \sigma_{P}^{2} .
$$

We are now ready to compare expected welfare under the different regimes.

\footnotetext{
${ }^{2}$ The results for $P_{F}$ strictly positive are qualitatively similar, as long as $P_{F}$ is small, as explained later.
} 


\subsection{Private provision versus corruption}

In what follows we compare the expected social welfare in an economy where provision of the public good is always privatized with that of an economy where the decision whether to privatize is taken by a corrupt politician.

Denote the expected social welfare under privatization by $\bar{W}_{P}$ where

$$
\bar{W}_{P}=\int_{0}^{1} W_{P}\left(\sigma^{2}\right) d \sigma^{2}
$$

and consider the difference $\bar{W}_{C}-\bar{W}_{P}$ which can be expressed as

$$
\bar{W}_{C}-\bar{W}_{P}=\int_{0}^{1 / 2}\left[\bar{W}_{G}-W_{P}\left(\sigma_{P}^{2}\right)\right] d \sigma_{P}^{2} .
$$

Notice that for $\sigma_{P}^{2} \geq \frac{1}{2}$ a corrupt politician succeeds to extort a bribe and provision is private. Therefore, the two regimes only differ for $\sigma_{P}^{2}<\frac{1}{2}$.

As stated in Proposition 1, it turns out that corruption always leads to higher expected social surplus than private provision.

Proposition 1. For any value of $\delta, \bar{W}_{C} \geq \bar{W}_{P}$.

Proof. Define $\hat{\sigma}^{2}$ such that $W_{P}\left(\hat{\sigma}^{2}\right) \equiv \bar{W}_{G}$. Then

$$
\hat{\sigma}^{2}=\frac{\delta+3}{2(1-\delta)(2+\delta)^{2}} .
$$

Therefore $\hat{\sigma}^{2}$ is an increasing function of $\delta$ and it takes value $\frac{3}{8}$ for $\delta=0$. We consider two cases.

First case: $\delta<\bar{\delta}$. In this case $W_{P}(0)=0<\bar{W}_{G}<\bar{W}_{P}=W_{P}\left(\frac{1}{2}\right)$. Since $W_{P}\left(\sigma^{2}\right)$ is continuous and strictly increasing in $\sigma^{2}$, it follows that $\hat{\sigma}^{2}<\frac{1}{2}$.

Write the difference $\bar{W}_{C}-\bar{W}_{P}$ as the sum of two elements:

$$
\bar{W}_{C}-\bar{W}_{P}=\int_{0}^{\hat{\sigma}^{2}}\left[\bar{W}_{G}-W_{P}\left(\sigma_{P}^{2}\right)\right] d \sigma_{P}^{2}+\int_{\hat{\sigma}^{2}}^{1 / 2}\left[\bar{W}_{G}-W_{P}\left(\sigma_{P}^{2}\right)\right] d \sigma_{P}^{2} .
$$

Notice that the first integral is positive and the second is negative; therefore, in order for $\bar{W}_{C}-\bar{W}_{P}$ to be positive, we need the first element to be larger (in absolute value) than the second. Since $W_{P}\left(\sigma_{P}^{2}\right)$ is a linear function of $\sigma_{P}^{2}$, this occurs for $\hat{\sigma}^{2}>\frac{1}{4}$. But this follows easily, because $\hat{\sigma}^{2}$ is an increasing function of $\delta$ and $\hat{\sigma}^{2}(0)=\frac{3}{8}$.

Second case: $\delta>\bar{\delta}$. We now have $\bar{W}_{P} \leq \bar{W}_{G}$ and, as before, $W_{P}\left(\sigma^{2}\right)$ is continuous and increasing. Thus $W_{P}\left(\sigma^{2}\right)<\bar{W}_{G}$ for any $\sigma^{2}<\frac{1}{2}$. It follows that

$$
\bar{W}_{C}-\bar{W}_{P}=\int_{0}^{1 / 2}\left[\bar{W}_{G}-W_{P}\left(\sigma^{2}\right)\right] d \sigma^{2}>0 .
$$

According to Proposition 1, expected social welfare is larger when a self-interested corrupt politician decides whether to privatize or not than under privatization; this is true regardless of the value of $\delta$, a measure of the social cost of effort.

Fig. 1, which is drawn for $\delta=0,{ }^{3}$ illustrates Proposition 1. The picture shows the areas corresponding to expected social welfare for the two regimes: the gray shaded area represents corruption while the striped area corresponds to privatization; as we already know, the two completely overlap for $\sigma^{2}$ greater than $\frac{1}{2}$.

To get an intuition of why the result holds notice that when the efficiency $\sigma$ of the private manager is low, two things happen: first, privatization leads to low social welfare and, second, a corrupt politician asks for a bribe too high for a low efficiency manager to pay. Therefore, corruption produces a positive selection effect that leads to privatize only when the efficiency of the private manager is higher than the average public bureaucrat's. This positive selection effect is what makes corruption preferable to privatization from the point of view of social welfare.

Notice that a similar positive selection effect could also be obtained without the bribe by asking a strictly positive price $P_{F}>0$ for the facility. In this model, in fact, the bribe $B$ and the price of the facility $P_{F}$ have the same nature since they are both prices paid by the private manager. ${ }^{4}$

Therefore, if $P_{F}$ was strictly positive, total welfare in case of privatization would be higher than the value $\bar{W}_{P}$ we computed above. However, even so, for $P_{F}$ small there might be space for a corrupt politician to make the private manager pay a bribe in addition to the price $P_{F}$ and such a bribe would make a further positive selection (above the one obtained through $P_{F}$ ) that might be beneficial in terms of welfare. ${ }^{5}$ This is why the result we obtained is robust with respect to the price of the facility, as long as $P_{F}$ is not too large.

\footnotetext{
${ }^{3}$ The origin of the axis is $\left(0, B_{0}-C_{0}\right)$. Notice that the picture would be qualitatively similar for any value of $\delta<\bar{\delta}$, whereas for $\delta>\bar{\delta}$ we have $W_{P}\left(\frac{1}{2}\right)<\bar{W}_{G}$.

4 The fact that they differ in the person cashing has no consequences on total welfare.

${ }^{5}$ See the discussion in Section 4 on what makes the positive selection of the bribe beneficial when $P_{F}$ is positive.
} 


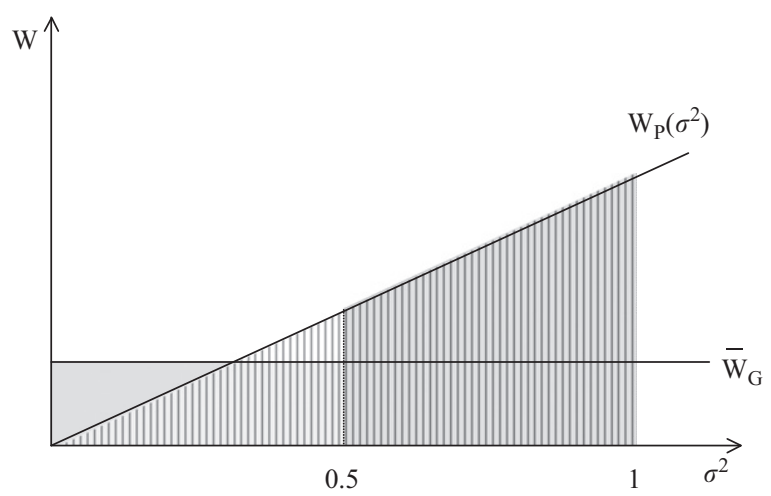

Fig. 1. Expected social welfare under corruption and privatization.

\subsection{Public provision versus corruption}

We now turn to the comparison of provision under corruption versus public provision. Write the difference $\bar{W}_{C}-\bar{W}_{G}$ as

$$
\bar{W}_{C}-\bar{W}_{G}=\int_{1 / 2}^{1}\left[W_{P}\left(\sigma_{P}^{2}\right)-\bar{W}_{G}\right] d \sigma^{2}
$$

Notice that now the two regimes lead to the same expected social welfare for $\sigma^{2}<\frac{1}{2}$ because in this range the private manager refuses to pay the bribe and provision is public. Therefore the two regimes only differ in the interval $\frac{1}{2} \leq \sigma^{2} \leq 1$.

As stated in the next proposition, the ranking of the two regimes now is not independent on the value of $\delta$, the social cost of the cost reducing effort.

Proposition 2. There exists a $\overline{\bar{\delta}} \in(\bar{\delta}, 1)$ such that, for any $\delta<\overline{\bar{\delta}}$ we have $\bar{W}_{C}>\bar{W}_{G}$ and for any $\delta>\overline{\bar{\delta}}$ we have $\bar{W}_{C}<\bar{W}_{G}$.

Proof. We consider two cases.

First case: $\delta<\bar{\delta}$. In this case $W_{G}\left(\sigma^{2}\right)<W_{P}\left(\sigma^{2}\right)$ for any $\sigma^{2}$. Therefore $\bar{W}_{G}<\bar{W}_{P}<\bar{W}_{C}$, where the last inequality follows from Proposition 1.

Second case: $\delta \geq \bar{\delta}$. Define $\hat{\sigma}^{2}$ as in the proof of Proposition 1. We know that $\hat{\sigma}^{2}$ is increasing in $\delta$ and $\hat{\sigma}^{2}=\frac{1}{2}$ when $\delta=\bar{\delta}$ If $\hat{\sigma}^{2} \leq 1$ we write the difference $\bar{W}_{C}-\bar{W}_{G}$ as the sum of two elements:

$$
\bar{W}_{C}-\bar{W}_{G}=\int_{1 / 2}^{\hat{\sigma}^{2}}\left[W_{P}\left(\sigma^{2}\right)-\bar{W}_{G}\right] d \sigma^{2}+\int_{\hat{\sigma}^{2}}^{1}\left[W_{P}\left(\sigma^{2}\right)-\bar{W}_{G}\right] d \sigma^{2} .
$$

Notice that the first integral is negative and the second is positive and, by linearity of $W_{P}\left(\sigma^{2}\right)$, the two integrals are equal when $\hat{\sigma}^{2}=\frac{3}{4}$.

If, instead, $\hat{\sigma}^{2}>1$ then $W_{P}\left(\sigma^{2}\right)<\bar{W}_{G}$ for any value of $\sigma^{2} \in[0,1]$ and

$$
\bar{W}_{C}-\bar{W}_{G}=\int_{1 / 2}^{1}\left[W_{P}\left(\sigma^{2}\right)-\bar{W}_{G}\right] d \sigma^{2}<0 .
$$

We conclude that $\bar{W}_{C}-\bar{W}_{G}$ is positive for $\frac{1}{2}<\hat{\sigma}<\frac{3}{4}$, zero for $\hat{\sigma}=\frac{3}{4}$ and negative for $\hat{\sigma}>\frac{3}{4}$. The equation $\hat{\sigma}=(\delta+3) / 2(1-\delta)(2+\delta)^{2}=\frac{3}{4}$ determines the value of $\overline{\bar{\delta}}=0.6542$.

The conclusion of Proposition 2 for $\delta<\bar{\delta}$, i.e. when the social cost of effort is small, is straightforward: since in this case public provision is worse than privatization, corruption is the overall preferred regime. For higher values of $\delta$, however, things are more complex: when the social cost of effort raises above $\bar{\delta}$, the positive selection effect of corruption is increasingly offset by the fact that private provision is socially inefficient and it is not clear which force is stronger. As it turns out, for sufficiently high values of $\delta$, the second effect prevails and public provision becomes preferable to letting a corrupt politician decide the provision regime.

The results of Propositions 1 and 2 are summarized in Fig. 2 where we compare expected welfare in the three regimes as a function of $\delta$. In the figure, the black straight line is $\bar{W}_{P}$ and the gray one is $\bar{W}_{C}$; as stated in Proposition 1, the first always lies below the second. These two lines intersect the curve $\bar{W}_{G}$ in $\bar{\delta}$ and $\bar{\delta}$ respectively. 


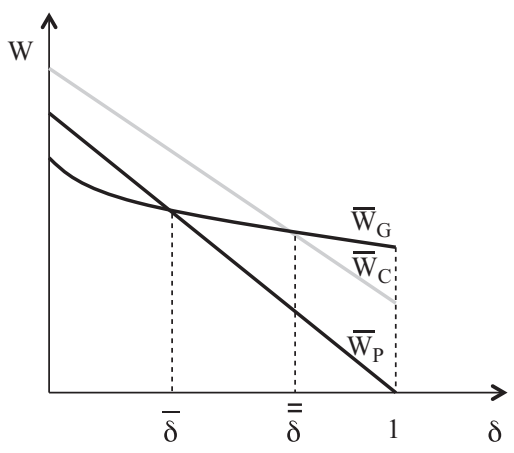

Fig. 2. Expected social welfare comparison as a function of $\delta$.

\section{A comment on the generality of the model}

The model considered so far is very simple; its main advantage is to allow for easy-to-compute, closed form solutions of the equilibrium expected social welfare functions under the different regimes. However, our result that corruption may play a positive selection effect holds in much more general contexts.

Consider a situation where there is a trade-off between public and private provision: when the negative externality on quality of the cost reducing effort is small, that is, for low values of $\delta$, private provision is more favorable; otherwise public provision is better. When this is not the case, one of the two regimes is definitely superior and the choice of the regime should not be left to a politician that would expose it to the risk of being based on corruption. In other words, we believe that the question "who scores better between a corrupt politician and a benevolent one" is, in this context, of a more practical interest when the politician has a role to play in evaluating the social costs and benefits of the two regimes.

To prove that the private regime is always worse, in terms of social welfare, than corruption, we used three key elements; in what follows we discuss them and we explain why they should hold in general.

The first element is the fact that the bribing system selects the most efficient private managers. This fact follows from the assumption that the private manager's profit is increasing in $\sigma$, the cost reducing efficiency. This assumption seems natural in most reasonable representations of this problem.

The second element is that the comparison between social welfare under corruption and that obtainable with privatization is monotonic in $\delta$, which measures the magnitude of the social cost of effort. In our model, this follows from the fact that $\bar{W}_{G}$ decreases with $\delta$ at a slower speed than $W_{P}(\sigma)$ does. Notice that both $\bar{W}_{G}$ and $W_{P}(\sigma)$ are decreasing in $\delta$; this is so because under both regimes the cost reducing effort is positive and, therefore, all other things being equal, the higher is $\delta$ the lower is social welfare. However, they decrease at a different speed: in fact, the cost reducing effort is decreasing in $\delta$ under public provision, thanks to the fact that the latter regime partly internalizes the negative effect of effort on quality and, thus, on social welfare. Under privatization, instead, effort is independent on $\delta$. Therefore the public provision regime is better than the private one in internalizing the social cost of effort. This is likely to be a common characteristic of this problem, holding outside of our special model.

The third and last element that plays a role in our proof is the fact that, for $\delta=0$, the managers left out under corruption, in other words those who do not pass the filter of the bribing system, produce, on average, a smaller expected social welfare than the average public bureaucrat. It is hard to tell whether this condition holds in general, since it depends (i) on the relative magnitude of $W_{P}(\sigma)$ and $\bar{W}_{G}$, (ii) on the probability distribution of $\sigma_{G}$ and $\sigma_{P}$, i.e. on the distribution of the cost reducing efficiency in the public and private sector and, if the price of the facility $P_{F}$ is strictly positive, (iii) on how large $P_{F}$ is. So it is this third fact that will likely decide, in a more general model, whether the result holds true. ${ }^{6}$

\section{Conclusion}

We have focused on corruption in the privatization process and on its effect on social welfare when there is asymmetric information on the public and private manager's efficiencies. Our analysis reveals one of the mechanisms through which corruption may be beneficial: it can play a positive selection effect on the efficiency of the private firm. This is not to say that Governments should not be worried about corruption or, worst, encourage it. In fact, there might be other forces at play, that we have not included in our simple model, and whose consequences are not so desirable (see, for example, Bjorvatn and Soreide, 2005). But, certainly, unveiling this mechanism could help reconcile some ambiguous empirical results.

\footnotetext{
${ }^{6}$ More precisely, given the monotonicity in $\delta$, if for some $\delta^{\prime}$ the expected value of the social welfare under privatization conditional on the set of manager's types not accepting to pay the bribe is smaller than the overall expected value of social welfare under public provision, then we expect social welfare to be higher under corruption than under privatization, for any $\delta \geq \delta^{\prime}$.
} 


\section{Acknowledgments}

We wish to thank M. Li Calzi for helpful comments.

\section{References}

Aidt, T.S., 2003. Economic analysis of corruption: a survey. Economic Journal 113 (4), F632-F652.

Bardhan, P., 1997. Corruption and development a review of issues. Journal of Economic Literature 34, 320-346.

Beck, P.J., Maher, M.W., 1986. A comparison of bribery and bidding in thin markets. Economic Letters 20, 1-5.

Bjorvatn, K., Soreide, T., 2005. Corruption and privatization. European Journal of Political Economy 21 (4), $903-914$.

Chong, A., Lopez de Silanes, F., 2004. Privatization in Latin America: What does the evidence say. Economia: Journal of the Latin American and Caribbean Economic Association 4 (2), 37-94.

Clark, D., Riis, C., 2000. Allocation efficiency in a competitive bribery game. Journal of Economic Behavior \& Organization 42 (1), $109-124$.

de Vaal, A., Ebben, W., 2011. Institutions and the relation between corruption and economic growth. Review of Development Economics 15 (1), 108-123.

Dong, B., Torgler, B., 2010. The Consequences of Corruption: Evidence from China. CREMA Working Paper Series, 2010-07. Center for Research in Economics, Management and the Arts (CREMA).

Dreher, A., Herzfeld, T., 2005. The Economic Costs of Corruption: A Survey and New Evidence. EconWPA, Public Economics 0506001.

Everhart, J., Martinez-Vazquez, J., McNab, R., 2009. Corruption, governance, investment and growth in emerging markets. Applied Economics 41 (13), 1579-1594.

Halkos, G., Tzeremes, G., 2010. Corruption and economic efficiency: panel data evidence. Global Economic Review 39 (4), $441-454$

Hart, O., Shleifer, A., Vishny, R.W., 1997. The proper scope of government: theory and an application to prisons. Quarterly Journal of Economics 112 (4), 1127-1161.

Jain, A.K., 2001. Corruption: a review. Journal of Economic Surveys 15 (1), 71-121.

Kaufmann, D., Siegelbaum, P., 1997. Privatization and corruption in transition economies. Journal of International Affairs 50 (2), $419-458$.

Laffont, J.J., Meleu, M., 1999. A positive theory of privatisation for sub-Saharan Africa. Journal of African Economies 8 (1), $30-67$.

Lien, D., 1986. A note on competitive bribery games. Economics Letters 22, 337-341.

Lien, D., 1990. Corruption and allocation efficiency. Journal of Development Economics 33, 153-164.

Lu, M., Chen, Z., Zhang, S., 2008. Paying for the dream of public ownership: case studies on corruption and privatization in China. Transitional Studies Review 15, 355-373.

Lui, F.T., 1985. An equilibrium queuing model of bribery. Journal of Political Economy 93 (4), 760-781.

Murphy, K.M., Shleifer, A., Vishny, R.W., 1993. Why is rent-seeking so costly to growth? American Economic Review 83 (2), $409-414$

Rose-Ackerman, S., 1997. The political economy of corruption. In: Elliott, K.A. (Ed.), Corruption and the Global Economy. Peterson Institute, Washington, DC. pp. 31-60.

Rose-Ackerman, S., 1999. Corruption and Government: Causes Consequences and Reform. Cambridge University Press, Cambridge, UK.

Shleifer, A., 1998. State versus private ownership. Journal of Economic Perspectives 12 (4), 133-150. 